\title{
Living on a knife edge: the responses of people with physical health conditions to changes in disability benefits
}

\author{
Jessica Saffer, Lizette Nolte \& Simon Duffy
}

\begin{abstract}
This article documents the experiences of people with a physical health condition or disability who have experienced a loss of or change in disability benefits under the welfare reform programme in the United Kingdom. A theoretical model was constructed using in-depth interviews and grounded theory methods. The findings show that participants experienced the benefits system as dehumanising, and felt that they lived in a judgemental and invalidating society, where they were perceived as 'scroungers' and faced discrimination from others. These experiences negatively affected their mental and physical health and wellbeing. They also negatively affected participants' identity, leading to experiences of shame, hopelessness and social isolation. However, many participants attempted to resist these negative impacts (e.g. through seeking support or taking political action). The findings demonstrate the significant impact of benefit changes on well-being and identity, thus highlighting important implications for claimants, and staff in healthcare, the benefits system and government.
\end{abstract}

\section{Points of interest}

- $\quad$ The research discovered that disabled people found the benefits system unpredictable and difficult to understand, which was very distressing.

- $\quad$ The research also found that many disabled people felt judged and treated unfairly for claiming benefits.

- $\quad$ These experiences led to poorer mental and physical health, and to some disabled people becoming socially isolated

- Many disabled people tried to fight against the stigma of claiming benefits, for example by appealing their benefits decisions and seeking support from others.

- $\quad$ The research recommended that the government needs to change the benefit system to make it less stressful for claimants, and that there needs to be more support for disabled people who claim benefits.

\section{Introduction}

Living with a disability is associated with higher costs of living, including costs of specialist equipment or appliances (NPI 2016). Furthermore, there has been a rise in the cost of living in the United Kingdom above the average rate of inflation (HM Treasury 2012), including energy bills and food, water and transport costs (Adams, Hood, and Levell 2014). Additionally, for many living with a disability, access to work is limited, both due to the impairments associated with their conditions and a lack of accessibility and inclusion within the labour market. Therefore, while disabled people have higher financial needs, they are likely to be less able to meet these needs and disabled people are reported to be twice as likely to live in poverty as non-disabled people (NP1 2016).

The UK government views those with a disability as entitled to social aid through the UK welfare system. However, a clear definition of 'disability', and thus who is entitled to such support, does not exist 'naturally', but rather has been described as an 'administrative category' defined by society, that continues to be redesigned and then enforced by subsequent governments (Roulstone 2015; Stone 1984). Therefore, changes to disability benefits in the United Kingdom can be defined as a political act and must be understood in 
the context of a range of different developments, some of which are specific to disabled people, while others relate to broader ideological or economic factors.

Historically, after World War II the welfare state in the United Kingdom went through a significant period of development and expansion. However, specific measures to support disabled people were limited and often came in the form of institutional care (Spicker 2011). It was not until the 1970s, particularly as disabled people became better organised, that some new benefits such as the Disability Living Allowance were introduced, in order to assist people with the extra costs of daily living (Royston 2017). Since at least the 1980s, progressive developments in the welfare state have been more uncertain for disabled people. Government policy has increasingly used the language of disability rights, independent living and inclusion. However, many of the actual changes seem more negative. For instance, the Employment Support Allowance (ESA), which was first implemented in 2008, reduced eligibility, introduced new, more stringent forms of assessment (Grover and Piggott 2013) and added new controls over the behaviour of disabled people, including regular re-testing (Dwyer 2010). Privatisation of testing to non-government agencies (e.g. ATOS and Capita) adds an additional layer of complexity to the system.

In 2008 there was a severe global financial crisis and the UK government spent significant amounts on subsidising the banking sector. Such financial crises are often followed by what becomes defined as a crisis in social policy, and thus an opportunity to review welfare spending, including a review of the category of 'disability' (Roulstone 2015; Stone 1984). In 2010 the Coalition Government (Conservative and Liberal Democrat) introduced an austerity programme to curb public spending, which it has been argued is driven by the aim of radically reducing the overall level of public spending (Taylor-Gooby and Stoker 2011). Moreover, it has been argued that the balance of this austerity programme was significantly skewed in ways that were particularly damaging to the interests of disabled people (Duffy 2013). For example, the most severe targeting of cuts was on local government, who were responsible for providing social care for disabled children and adults (Duffy 2013). The Independent Living Fund, which supported disabled people with high support needs to live independently, was closed in June 2015 for claimants in England and Wales, although not in Scotland and Northern Ireland, showing some divergence across the United Kingdom in terms of support for disabled people. Moreover, the implementation of existing policies (such as the introduction of the ESA) or the development of new policies, such as the replacement of Disability Living Allowance with the Personal Independence Payment (PIP), were all linked to planned cuts in overall spending on benefits (Roulstone 2015; Royston 2017).

With many complex and overlapping changes happening at the same time, to a diverse population, research on the impact of the changes is often patchy, or focused on one group or one particular policy change. However, various efforts have been made to map the overall impact of these changes on disabled people and each concludes that the impact is severe and negative (Duffy 2014; Reed and Portes 2014). Research links financial difficulties to a pronounced adverse impact on both physical and mental health (Richardson, Elliott, and Roberts 2013). This includes poor health in mid-life (Arber, Fenn, and Meadows 2014) and loss of mobility affecting freedom of movement (Power 2016). It also includes increased mental health problems (for example, Fitch et al. 2011) and self-harm and suicide risk (Barnes et al. 2016; Corcoran et al. 2015; Stack and Wasserman 2007). Such has been the unusually 
severe nature of these cuts that the United Kingdom has been subject to strong criticism by various United Nations committees, who have drawn particular attention to the combination of cuts in disability benefits and the cuts to social care (UNCESCR 2016; UNCRPD 2016; UNCRC 2016). The UNCRPD $(2016,3)$ described 'systematic violations' of the rights of disabled people, commenting on financial hardship and scapegoating of disabled benefit claimants, and called for the benefit cuts that came through the 2012 and 2016 Welfare Reform Acts (DWP 2012, 2016) to be reversed.

In addition to the impact of financial hardship, the process of applying and being assessed for benefits has been linked to stress and a negative effect on mental health (Barnes et al. 2016; McCartney 2012, 2015). The Work Capability Assessment, which assesses for the ESA, has been linked to significant increases in suicides, self-reported mental health problems and antidepressant prescribing (Barr et al. 2016). Benefit receipt is known to involve stigma and shame (for example, Baumberg 2016); and benefit claiming is associated with negative stereotyping (for example, Garthwaite, Bambra, and Warren 2013; Grover and Piggott 2010), including the rhetoric of 'shirkers' and 'scroungers' (for example, Briant, Watson, and Philo 2013; Garthwaite 2011; McEnhill and Byrne 2014). It is noticeable that the public discourse surrounding benefit claimants has dramatically shifted in recent times, leading to a marked rise in the negative stigma related to applying for benefits (Park et al. 2012). There is no doubt that this stigmatised view of claimants has an impact on their day-to-day lives, including neighbourhood civilities (Airey 2003), how comfortable claimants feel when talking to others (Garthwaite 2015b) and increased experiences of hate crime (Thomas 2011).

Researchers have drawn on extensive empirical evidence to document the experiences of making disability benefit claims and of living as a benefit claimant, making it evident that being a claimant has many complex aspects. Some of this research has looked at this topic from a poverty or disability perspective, where the welfare system formed a small part of the research, and other studies have combined data about many types of benefit claimants (Pemberton et al. 2016a, 2016b; Patrick 2014). This makes it difficult to make firm conclusions about the experiences and identity of people with physical disabilities. As the benefit system continues to change, previous research, whilst still valuable, can become outdated. de Wolfe (2012) emphasised the need for more and ongoing research on claimants' experiences, given the recent tightened benefits criteria which generate greater anxiety and risk of impoverishment. Therefore a focused piece of research on the experiences of people with physical disabilities since the recent changes to the benefits system was considered to be valuable in contributing to the growing body of research.

\section{Research aims}

This study aimed to investigate the experiences and identity of people with physical health conditions who make disability benefit claims and live as claimants in the current political climate within the United Kingdom since 2010. The research question was 'What is the impact of a loss of or change in disability benefits on the experiences and identity of people with physical disabilities?' The research investigated how a change in disability benefits has affected individuals' daily functioning and physical health; emotional well-being; ability to participate or engage with their community; how others, including family, friends and members of the public, respond to claimants; and sense of self. Two consultants living with 
disability, one of whom works as a disability advocate, offered guidance about increasing the relevance and focus of the research and gave feedback on the information sheets and interview schedule. This research sought to develop a theoretical model that could explain the experiences of disabled benefit claimants in the current political climate within the United Kingdom.

\section{Method}

A qualitative research design was employed and constructivist grounded theory (Charmaz 2014) was used to analyse the data. This allowed for the analysis to be situated within its social context and for capturing of context and political voices. It also acknowledges the role of the researchers' positions, perspectives and interactions in the research.

\section{Participants}

Participants were required to have a minimum of one long-term physical health condition or disability and to have experienced changes to their disability benefits since 2010 to be included in the study, regardless of whether they also experienced co-morbidities such as other physical health conditions or mental health problems. Initial recruitment was through disability charities and snowballing methods. Recruitment was also expanded to social media, including Twitter and Facebook, which involved sharing a link to a webpage with information about the study. Four participants were recruited from two disability charities, one by word of mouth and 10 through social media. The latter method of recruitment may have been more successful as it facilitated access to a larger number of potential participants, including those whose disabilities meant they could not access support in person.

\section{Data collection}

This study used individual semi-structured interviews with people who had personal experience of claiming disability benefits. The interview schedule was adjusted to feedback from a pilot interview. Questions included: 'How has your life changed since a loss of disability benefits?', with prompts such as 'daily functioning' and 'mood'; and 'How has losing your benefits changed how others feel about you?' Interviews were conducted either face to face or via Skype as per the interviewee's preference, and lasted between 25 and 85 minutes. As grounded theory is an iterative process, the guide was tailored over the course of the study in order to explore new issues brought up by interviewees (Charmaz 2014). For example, in the later interviews, participants were asked whether ideas from the draft grounded theory model resonated with people with visible disabilities as much as for people with invisible disabilities. Saturation was obtained after 15 interviews. Table 1 presents the demographics of the participants, using pseudonyms to maintain confidentiality.

The sample consisted of four males and 11 females, with an age range of 28-68 years, from various locations in the United Kingdom and various diverse ethnic and socio-economic backgrounds. Four of the participants had visible disabilities, and the others had invisible physical health conditions.

\section{Ethical considerations}


Ethical approval for this study was granted by the relevant Health and Human Sciences Ethics Committee. A number of ethical issues were considered throughout this research, including gaining informed consent and confidentiality (BPS 2009). Managing potential distress caused by participants' financial or social conditions was a difficult issue during data collection. For example, one potential participant who disclosed suicidal ideation was signposted to the appropriate mental health services. This demonstrates the extent of distress caused by benefit changes.

\section{Analysis}

Data analysis followed Charmaz's (2014) guidelines for constructivist grounded theory, using constant comparative analysis. Initial analysis was carried out by the first author. Coding was checked by the second author, who also independently coded a sample of the data to allow for comparison. Additionally, some excerpts of the data were independently analysed to check that the codes captured the essence of participants' experiences. Theoretical sampling of people with visible disabilities was used to check the relevance of the findings to this population, and to further define the properties of emerging categories (Charmaz 2014). Memoing, diagramming and a reflective journal were used throughout to document and develop ideas about potential relationships between codes and categories. Use of NVivo software enabled ease of comparison of data.

[Table 1 here]

\section{Findings}

Findings were conceptualised in three domains, namely 'Navigating a dehumanizing system', 'Living in a judgemental society' and 'Clinging onto my sense of self', as outlined in Table 2.

[Table 2 here]

\section{Navigating a dehumanising system}

In the domain 'Navigating a dehumanising system', the impact on participants of trying to make sense of and engage with the benefits system is discussed. Participants described experiences of a dehumanising system, riddled with uncertainty and not fit for purpose. Two social processes were identified, namely 'Going on "a wild goose chase"' and 'Drowning in a climate of stress and fear'.

\section{Going on 'a wild goose chase'}

The benefits system was described by many participants as overwhelmingly complex. Some found it difficult to understand which benefits they were entitled to or even which they were receiving. Application forms and letters from the Department for Work and Pensions (DWP) were experienced as lengthy and confusing. Overall, interaction with the benefits system was described as 'a wild goose chase' (Eve), and this seemed to lead to suspicion of the system: 
Most participants felt that the assessment process used in the current benefits system was unsuitable for people who are unwell. Participants referred to the assessor's lack of knowledge about particular disabilities, particularly when the impairment is unseen, fluctuating or degenerative in presentation. Many emphasised the significant implications of not having assessors and decision-makers who are qualified on how particular disabilities affect people and wished that their own medical professionals could assess their suitability for benefit support:

You have assessors that are paramedics ... How do they know how to really assess someone's mental health problems? They don't! (Irene)

Furthermore, claimants were required to have separate assessments for each benefit they were eligible for, which was felt to be burdensome and unnecessary. Many participants complained that the assessment reports did not reflect their experiences of their difficulties and contained many errors. If participants appealed the DWP decision, then there was a long process, involving mandatory reconsideration and a tribunal. If claimants lost one benefit, this had an impact on the stability of their other benefits, described as a 'domino effect' (Louise):

I did a change of circumstances in March, um, because, this is when the muscle wastage started really affecting me, and that's when I got zeros across the board. (Irene)

Participants speculated that the assessment process was driven politically rather than needs driven, with many fearing that the system was intentionally complex and misleading in order to reduce the number of people who were receiving benefits:

It's like they seem like they are just having a chat with you but they are not. Like everything that you say is assessed against a criteria. (Oliver)

Thus, a deep distrust in the process was described by participants who found themselves trying to navigate a system experienced as unclear, unpredictable and unreliable, and over which they had no sense of control.

\section{Drowning in a climate of stress and fear}

The impact of this persistent insecurity appeared to be ongoing experiences of fear and stress, 'like an ongoing cycle of stressful assessments' (Frankie), as well as, for many participants, feelings of anger and frustration:

... anytime a brown envelope comes through my door I'm 'God no, what is it this time?' (Nicola)

For some participants, the responses to the relentless nature of the stress and uncertainty were particularly severe and disabling, leading to them feel frightened about becoming a burden on their families. They described being 'held in this climate of fear' (Caroline) and 'living on a knife edge' (Bryony), because they constantly anticipated changes to their benefits, knew these changes were unpredictable and could be sudden, and worried about the impact that this could have on their lives: 
I've been you know excessively worrying and, you know, just been really fearful and anxious about it all. (Caroline)

This fear prevented some participants from complaining when they felt they had been maltreated, as they feared retribution through further cuts to their benefits. Some avoided reporting changes in their conditions or attempting to appeal to receive a higher rate of benefit for fear of losing all of their benefits:

I've been told if I really want to get that component I have to go through the tribunal. But then I risk losing everything! (Louise)

Many participants described hearing (e.g. in online forums, in the media or through word of mouth) about the cuts to their benefits that other disabled people had faced and how this had impacted on their lives, including people who had died after they lost their benefits. They mentioned how cuts had affected friends' lives, such as worsening mental health, losing their homes, not having enough money to eat, losing access to carers and deaf people losing their sign language interpreters:

I had a friend who committed suicide because she was so scared she was going to be cut. (Bryony)

Hearing these 'horror stories' (Oliver) increased most participants' fears about their own situation. Therefore, this shows that hearing about others' difficulties may potentially have significant implications for claimants' own mental health. This is particularly significant within the current UK context where the lives of people who claim benefits are negatively portrayed daily on television, in print media and on social media.

In summary, in the domain 'Navigating a dehumanising system', participants described having no sense of agency in affecting a system that appeared to not have their interest at heart. Living with the ongoing uncertainty and stress that came from this was shown to have potentially significant detrimental implications for participants' well-being.

\section{Living in a judgemental society}

Participants were not only affected by their interactions with the benefits system, but were affected more widely in their everyday lives. In the domain 'Living in a judgemental society', the social processes occurring between benefit applicants and society, both in person and through portrayals in the media, are discussed. These are 'Bearing public scrutiny' and 'Being treated like shit under a shoe'.

\section{Bearing public scrutiny}

Most participants were aware of and felt personally affected by what they experienced as the current social and political scrutiny and judgement of benefit claimants. They felt that benefit claimants were perceived either to be lying about their illnesses or disabilities, 'scrounging', or lying about their inability to work, 'shirking'. They found the stereotype of benefits claimants extremely stigmatising, and described using derogatory language such as 
'benefit scum' (Frankie). They thought that this rhetoric permeates the attitudes of members of the public, leading to disabled people being judged as less worthy citizens:

... society looks down on you when you're claiming benefits. (Jonathan)

Several participants reflected on what seems to be a 'hierarchy' of disability, with some types of disability appearing to be deemed more 'legitimate' or 'valued' than others. A distinction was made between visible disabilities, including those requiring use of a wheelchair, and invisible disabilities, such as long-term health conditions leading to pain and fatigue, cognitive difficulties and mental health difficulties. Those with invisible disabilities felt frustrated that they were judged to be undeserving of benefits or adaptations for disabled people, such as sitting on public transport and having a blue badge, and therefore felt they had to justify their disabilities:

I feel that they are cynical or sceptical about my disability because I appear to be quite normal. (Kelvin)

Many participants felt that the media and the government exacerbated and perpetuated such disparaging perceptions of claiming benefits as a 'lifestyle choice', embedding implied assumptions that those claiming benefits are 'lazy' and 'deviously stealing' from taxpayers. For example, frequent television coverage, or 'benefit porn' (Grace), showing the lives of people receiving benefits for the entertainment of others, was described as 'media brainwashing' (Caroline) that affected the views of the audience:

You look at the press it's always about the benefits. You know Channel 5 all their programmes: 'Life on Benefit Street', 'Holiday on benefits' and things like that... (Adrienne)

There was a sense that this government and media scrutiny in some ways gave 'permission' to denigrate others' 'lifestyle choices', leading to members of the public taking on a surveillance and policing role. This left participants vulnerable to confrontation and intimidation while engaging in everyday activities:

I've been told off for sitting on the bus. It's for disabled people, why are you sitting there, it's for disabled people or for old people. And I said actually I'm in a lot of pain and I can't stand for very long. (Adrienne)

There was a deep sense of being misunderstood by those who did not have in-depth knowledge of or personal contact with the benefits system.

... they know that the benefits system has changed but I don't think that they realise the suffering. (Louise)

Being treated like shit under a shoe

Due to the ignorance and judgement they faced as benefit claimants, many participants described that they were treated unjustly, and even bullied, by staff in the benefits system and by the general public: 
Participants described being treated unfairly, rudely, disrespectfully, patronizingly and even threateningly, and they often felt distressed and frustrated as a consequence:

... and when I went to the job centre the person there who I saw was really rude to me and I ended up in absolute tears ... (Caroline)

Many participants experienced not being listened to or cared about and feeling humiliated. This powerfully reinforced a sense in many participants of not being valued as equal citizens in society:

... you have to take all your tablets in (to the benefits assessment). And I take quite a lot so basically l've got a bag full of tablets and she managed to tip them all on the floor and then watched me for five minutes trying to pick them up before she bothered offering any help. (Grace)

These painful experiences angered the participants, and also led to fear, even preventing some from going out:

I'd park up, put the blue badge out, get out of my car and then somebody comes over to you and starts to give you a lecture because in their mind you don't look sick to them. (Frankie)

In the domain 'Living in a judgemental society', participants described that the focus on and judgement of those claiming benefits can have a significant influence on participants' freedom and confidence to go about their daily lives. Exposure to such blaming societal discourses, and distressing confrontations with those who challenge the 'validity' of their experiences as disabled and chronically unwell persons, deeply affected participants' sense of themselves as equal citizens in society.

\section{Clinging onto my sense of self}

Lastly, in the domain 'Clinging onto my sense of self', the impact of both navigating a dehumanising benefits system and living in a judgemental society for participants' quality of life and sense of self is discussed, including 'Lacking resources to sustain my physical and mental health' and 'Losing a sense of myself'.

\section{Lacking resources to sustain my physical and mental health}

Participants described that navigating the benefits system and living in a judgemental society led to them having difficulties with finances, having difficulties with health and, as a result, being able to do less. Most participants said that they did not want to rely on benefits; however, given their health condition or disability and, for some, inability to work, they were dependent on their benefits and therefore struggled financially if their benefits were suddenly reduced:

So it kind of threw me into this financial mess ... I've ended up in debt and overdrawn. (Caroline) 
Many participants experienced difficulties paying for necessities, including paying bills and being able to feed and care for themselves, their children and their pets:

I wouldn't have been able to pay the electricity, the gas, the water bill, the heating bill and eat. It would have to be one or the other. (Adrienne)

It seemed that lacking finances to maintain these participants' health led to further ill health, which in turn reduced the possibility of working and led to increasing financial problems:

So if I'm stressed, if I'm very stressed then I get a flare-up and then sometimes I can't get out of bed for a week. (Adrienne)

All of the participants also described how their experiences within the benefits system and in society negatively affected their physical and mental health, leading to increases in psychological distress, including anxiety and low mood. Four participants mentioned feeling suicidal, with two describing the suicide attempts they had made:

And my condition did deteriorate after the news that I was going to lose [benefit] because ... I was becoming more depressed ... It was as if I couldn't live another day feeling the way I did. (Dean)

Furthermore, as a result of a poorer financial situation and poorer mental and physical health, most participants reported being able to do less. Some described feeling trapped, both in being financially unable to plan ahead as well as physically limited, for example in affording transport. This could become a vicious cycle, leading to some participants becoming socially isolated:

... it is a two-way thing so I am unable to go out because I feel awful and then because I can't go out I feel doubly awful. (Kelvin)

Losing a sense of myself

In addition to these restrictions that impacted on participants' mental and physical health and well-being, participants also described significant implications for their sense of self. Participants reported feeling like they were losing their previous known sense of self:

I used to teach and do reports. It's like I'm a completely different person. It's like your life's been taken away. (Adrienne)

Exacerbating these feelings was the way in which several participants felt they were required to present themselves as more disabled for benefits applications than they would in other social situations. This unusual public display of disability caused participants to focus on their limitations rather than their abilities, which had a detrimental impact on both mood and identity:

The focus has to be on all the things that you can't do in life ... certainly that isn't the way I tend to live my life and wouldn't be a way that would be helpful to live my life. 
So I think that if even if you have a strong sense of identity that filling in that form can be quite a miserable process. (Molly)

Participants described a loss of confidence, and many described an internalized discourse of self-judgement:

Judgements come along with that [telling people I claim benefits] ... Even my own self judgement. (Grace)

A few reported how these judgements, drawing on the dominant discourses about disability and benefit claimants, were internalised and also directed at others. For example, a few participants noticed themselves, and other disabled people, doubting one another. They described judging neighbours or people in the assessment waiting room to see whether they were 'genuinely disabled' enough to claim benefits, thus potentially turning disabled benefit claimants against one another:

... you see people on crutches and you think this guy has crutches but does he, is he putting this on when I really have a disability? (Kelvin)

Some commented that they felt uncomfortable when they noticed their self-surveillance and surveillance of others in relation to benefits claiming, realising that they had internalised this stigmatised perspective of disabled benefit claimants:

This woman's, her daughter drives around in the mobility car and she can lift half a tonne of gravel in the back yard! Yet walks out on the front road with a walking stick. I've even filmed her, this is how bad, this has got me, this is the bit I don't like, I've even filmed this woman doing it and just thought what are you doing, hating myself for it. (Grace)

Many participants described painful feelings of shame and internalized stigma, doubting their own worth because they claimed benefits:

And people like me have no worth because I'm not producing right now in terms of making anything. (Frankie)

These feelings of embarrassment and shame caused many participants to feel uncomfortable about disclosing their benefit claimant status to others. Consequently, many hid their status, and by implication also the challenges they were facing in relation to claiming benefits, sometimes even from close friends and family, thus closing themselves off from potential support:

It's private! I don't like the fact that I claim benefits for a start. (Grace)

For some, the shame associated with claiming benefits even deterred them from claiming benefits that they were entitled to, or leading them to claiming less than they could have done. The distressing experiences described had the potential for devastating implications for participants. Many reported that, at times, they felt like giving up and they communicated a 
sense of powerlessness to change their adverse circumstances. Some lost hope about their futures, shown by giving up applying for benefits or attempting to end their lives:

... I thought 'I can't go through another battle' ... I just didn't think it was worth it, I just didn't want to go through any more. (Frankie)

Despite the overwhelming and pervasive nature of these experiences, many participants also described fighting to shake off a stigmatised identity. There were a number of ways in which participants distanced themselves from the stigma surrounding benefit claimants; they seemed to be resisting maltreatment and struggling to cling onto a preferred sense of self. Most participants described fighting against feelings of hopelessness and attempting to maintain a sense of hope about the future. Many told of imagining and striving for a healthier future, and this often included a hope for future employment and a move away from reliance on benefits:
Me, l'd rather have a job and be able to buy my girl better things and look after her better you know. I don't want to be taking money like this, just to live and buy food ... (Jonathan)

Some participants distanced themselves from the stigma of claiming benefits by justifying their own entitlement to benefits whilst acknowledging that there are benefit claimants who are fraudulent. In this way, they challenged that the dominant narrative on welfare is applicable to them. Therefore, many appealed the decision about their benefits or re-applied for disability benefits:

But there's very few folk that's something for nothing, the majority of people are genuine. (Dean)

Many participants described how their political beliefs enabled them to separate themselves from a stigmatised identity, as they located responsibility for their difficulties with the government. They believed that the current challenges with claiming benefits were due to the government policy of austerity, and many believed that policy changes were deliberately designed to reduce the number of people claiming benefits. This protected them from selfblame:

... is it some sort of political thing that's fed into the media to give people a perception or to justify all these cuts in a way? (Caroline)

A few participants found purpose in becoming an activist; for example, campaigning for disabled people's rights in their local area or helping others with their benefits applications. Taking part in this research was seen by some as a further way to separate themselves from a stigmatising identity, as they hoped it would be helpful in addressing ignorance about disabilities and difficulties in the benefits system, and thus stimulating change:

If more people knew in general then quite possibly these cuts wouldn't take place in the first place. (Bryony) 
Some participants found support for both individual and political acts through solidarity with peers, using online groups or local charities to connect with others who shared similar experiences to themselves. This reduced isolation, and increased access to support, allowed the sharing of experiences and enabled collective resistance. Participants appeared to be motivated by the knowledge that they could help others in a similar position:

Cos so many of us are in this situation we just try and keep each other afloat really. (Bryony)

Finally, many participants reported seeking support from family and friends, charities, professionals and their pets, which appeared to mediate the impact of a negative sense of self. This came in the form of financial, emotional and practical support. However, while necessary, for some this was accompanied by a sense of discomfort or guilt:

\section{It's horrible being a burden on your family. (Adrienne)}

In summary, the domain 'Clinging onto my sense of self' describes how dehumanising experiences within the benefits system, as well as judgemental and stigmatising experiences in relation to social constructions of benefit claimants, had potentially devastating consequences for participants' quality of life and sense of self. However, many participants used a number of strategies to resist these conclusions in relation to themselves and fought to hold on to hope, both personally and collectively.

\section{Discussion}

The grounded theory model developed in this research (Figure 1) shows the relationship between the different social processes constructed in the study.

[Figure 1 here]

In this study, people who have been subject to recent changes to their disability benefits described their contact with the DWP benefits system as dehumanising, with the incomprehensibility, unpredictability and unreliability of the process leading to pervasive worry, fear and stress (Patrick 2017; Wright 2016). This created a deep distrust in the system (see also Marks et al. 2017). This study supports the findings of many researchers in this area, including those who found that the assessment processes may be viewed as not empathetic (Clifton et al. 2013; Dwyer et al. 2016) and as dehumanising (Allen et al. 2016; Patrick 2017; Dwyer et al. 2016), intimidating (Shefer et al. 2016) and depersonalising (Garthwaite 2014).

Furthermore, these experiences occurred within the current wider social and political context of intense scrutiny, judgement and stigmatisation of those claiming disability benefits as 'scroungers' or 'shirkers'. These views permeate the attitudes of members of the public (Briant et al. 2013), leaving disability benefit claimants vulnerable to scrutiny and confrontation from others. Incidents of maltreatment, both within the benefits system and in wider society, and verbal harassment were recounted throughout the current research. 
These findings are in line with existing research that highlighted the relationship between dominant public narratives about disability claimants and scrutiny from others, who can take on a surveillance and policing role (Briant et al. 2013; Garthwaite 2014; Patrick, 2014; Pemberton et al. 2016b). It seems that the political and media coverage of benefit claimants could give implicit permission to denigrate others' 'lifestyle choices' (Pemberton et al. 2016b). This seemed to lead to a sense of being misunderstood and of their suffering being unseen and unacknowledged (Baumberg- Geiger, 2016; Garthwaite et al., 2013). Such negative experiences of self seem to powerfully mirror and re-enforce one another across these contexts, creating a potent negative feedback loop.

This loop not only led to predictable financial hardship, but also to emotional hardship and, for many, social isolation (see also Garthwaite 2015a). Such consequences have also been highlighted elsewhere, as a sense of 'going without' (Patrick 2017, 296) and 'existing, not living' (Pemberton et al. 2016a, 11), and are linked to current signs of financial hardship in the United Kingdom, such as the increased use of foodbanks (Loopstra et al. 2015).

The current study highlights the impact of this negative loop, namely the powerful negative identity implications for those who are disabled and claiming benefits within UK society, illuminated by painful descriptions of experiences of shame, secrecy (see also Garthwaite 2015b; Patrick 2016), selfjudgement and internalised stigma. While identity has not been the main focus of research into the experiences of benefit claimants, there is significant evidence of the negative implications of stigmatisation and invalidation for those living with chronic illness or disability (Charmaz, 1983; Goffman, 1963). For example, it has been shown that when suffering is delegitimised, people are silenced and refrain from telling their story (Ware 1992 as quoted in B€ulow 2008). This can narrow people's options for gaining validation for such experiences or for social support. Furthermore, such dominant negative identity conclusions could be 'totalising' in that they could obscure other, potentially more affirming, aspects of identity (e.g. as friend, parent, partner, neighbour, etc.). It was highlighted in the current study how this could lead to feelings of worthlessness, loss of confidence, loss of hope (including considering suicide or attempting to take one's own life) and loss of a sense of validation as an equal citizen in their communities and in wider society.

The important role of identity in the process of recovery has been previously highlighted (Anthony 1993), while it was clearly shown in the current study that invalidation and a negative sense of self have significant negative implications for well-being (including mental and physical health) and quality of life (Garthwaite 2015a). It could therefore be argued that this undermines recovery and exacerbates existing health conditions, thus increasing the likelihood of reliance on disability benefits. Despite this, it was shown that many participants attempted to contest these identity conclusions about themselves and on behalf of others, resisting stigmatising judgements, reaching out to others and taking political action. For some, this involved trying to distance themselves from such negative identity conclusions, while ascribing these perceptions and views to 'others' as the 'true' 'shirkers' or 'scroungers' (also described by Garthwaite 2015a; Moffatt and Noble 2015; Shildrick and MacDonald 2013). In defending their own entitlement to benefits, but not contesting the socially constructed identity and stigma surrounding claiming benefits, this reduces the scope for alternative narratives (Patrick 2016) and social change. However, it could be argued that it should not be the case that the emotional work involved in challenging powerful dominant discourses 
should be the responsibility of those who are marginalised by such discourses. Having said this, some participants did challenge these discourses on behalf of themselves and others, through 'acts of resistance' (Wade 1997, 32). These acts may be seen as an issue of dignity, and they additionally provide alternative identity options to the stigmatised identity of 'benefit claimant' described.

\section{Implications}

This research aligns with others who have found that the benefits system is dehumanising and not fit for purpose (for example, Allen et al. 2016; Moffatt and Noble 2015). It reiterates the significant implications of the assessor's lack of knowledge about particular conditions and about the specific needs of people living with chronic health conditions or disabilities (Akers 2016; Dwyer et al, 2016), particularly when the impairment is invisible and variable in presentation (for example, Litchfield 2013). In particular, an inability to respond to the complexity and diversity of presentations of chronic illness and disability has been shown as a specific limitation.

However, it is important to consider these findings within the context of staff working in a stressful, and perhaps also dehumanising, environment, with targets for the length of telephone calls to claimants and the proportions of claimants in different categories of benefits (Gentleman 2012; Anonymous 2016). This means that staff are also distanced from their own humanity and are not given the time or agency to consider each claim on merit and in a personalised way. Therefore, in order to reduce the stress involved in claiming benefits, it would be necessary to make significant changes to the benefits system process, as well as providing additional training for assessment staff.

It could be argued that welfare reforms, for example introducing reassessments for disability benefits, have had a greater cost, both financially on public services, as worsened mental health leads to being less able to manage physical health conditions (KHP 2016), and societally, due to suffering and distress in the short and long term (PAA 2015). It seems that changes in the benefits system have had the opposite effect to those claimed by the government; for example in the National Wellbeing Programme (Cameron 2010), which stated the aim as to improve well-being and health outcomes. Therefore, there is an ongoing need for researchers to highlight the true day-to-day impacts of current welfare reforms.

The current research has highlighted the worrying implications for people living with the stigmatised identity of being a disabled person and a benefit claimant. Some reported that online support forums helped counter these negative effects (although this was not true for all), while others found a positive sense of self through the support of family and friends or through taking collective political action. Organising, expanding and facilitating access to these avenues of support might be helpful for disabled people.

\section{Limitations and future research}

This research makes a further important contribution to the literature that highlights the severe effects of current welfare reforms on people with physical disabilities. However, the findings need to be considered within the context of a few limitations to the research. Firstly, 
due to the recruitment strategy followed, it may be that those who were motivated to participate in the study had poorer experiences of the benefits system or were more politically engaged. Additionally, there are limitations to recruitment through social media (Morris 2013), which means this study may not represent the views of those in extreme poverty who cannot afford an Internet connection, those who have disabilities which limit access to the Internet and those who are isolated from other disabled people. Therefore, the results may underrepresent some groups of disabled people.

The current study makes a unique contribution to the literature in that it provides a focus on identity. Future research may usefully build on this; for example, by investigating how individuals counter the stigma of living with a disability and claiming benefits, and the impact of collective action on identity. Other research might explore to what extent online support helps or hinders positive identity development for disabled people, as previous research has explored its benefits (Morris 2013) while the current study has highlighted its potential adverse effect on some.

\section{Conclusion}

This study highlights again how attitudes to and experiences of welfare are inextricably linked, and tend to shape each other (Hudson et al. 2016). This study has made an important contribution to the research on the responses of people with physical health conditions to changes in disability benefits. While this grounded theory does not make claims of causation, it powerfully highlights the negative feedback loop between benefits claimants' experiences of the benefits system and the wider political and social context within which the system exists. It remains vital that the suffering caused by such dehumanising experiences as reported in this research is exposed and disseminated, especially in relation to how those claiming benefits experience themselves within our society. These findings are important, particularly in a time of ongoing welfare reform and debate about the nature and future of the welfare state. Whilst the research was carried out in the current UK context, it also has international resonance given the international focus on policies of austerity.

\section{Acknowledgements}

Warm thanks go to the participants for their time and effort.

\section{Disclosure statement}

No potential conflict of interest was reported by the authors.

\section{References}

Adams, A., A. Hood, and P. Levell. 2014. The Squeeze on Incomes, the IFS Green Budget 2014. London: Institute of Fiscal Studies.

Airey, L. 2003. "“Nae as Nice a Scheme as It Used to Be": Lay Accounts of Neighbourhood Incivilities and Well-Being." Health \& Place 9 (2): 129-37.

Akers, C. 2016. How Does It Feel to be Assessed? Sheffield: The Centre for Welfare Reform. Allen, K., C. Hale, K. Seton, and J. Newton. 2016. A deeply dehumanising experience M.E./ CFS journeys through the PIP claim process in Scotland. Report for Action for M.E. 
Anonymous. 2016. "I'm a DWP Call Handler and Have No Time to Care about Your Disability Claim." The Guardian, August 20, 2016. www.theguardian.com/public-leadersnetwork/ 2016/aug/20/work-pensions-disability-claim-call-handler-benefits-dwp.

Anthony, W. A. 1993. "Recovery from Mental Illness: The Guiding Vision of the Mental Health Service System in the 1990s." Psychosocial Rehabilitation Journal 16 (4): 11-23.

Arber, S., K. Fenn, and R. Meadows. 2014. "Subjective Financial Well-Being, Income and Health Inequalities in Mid and Later Life in Britain." Social Science \& Medicine 100: 12-20.

Barnes, M. C., D. Gunnell, R. Davies, K. Hawton, N. Kapur, J. Potokar, and J. L. Donovan. 2016. "Understanding Vulnerability to Self-Harm in Times of Economic Hardship and Austerity: A Qualitative Study." BMJ 6 (2): e010131.

Barr, B., D. Taylor-Robinson, D. Stuckler, R. Loopstra, A. Reeves, and M. Whitehead. 2016.

“First, Do No Harm': Are Disability Assessments Associated with Adverse Trends in

Mental Health? a Longitudinal Ecological Study." Journal of Epidemiology and

Community Health 70 (4): 339-45.

Baumberg, B. 2016. "The Stigma of Claiming Benefits: A Quantitative Study." Journal of Social Policy 45 (02): 181-99.

Baumberg-Geiger, B. 2016. Benefit 'myths'? The accuracy and inaccuracy of public beliefs about the benefits system. No. 199. Centre for Analysis of Social Exclusion, LSE.

BPS (British Psychological Society). 2009. Code of Ethics and Conduct. Produced by the Ethics Committee of the British Psychological Society. Leicester.

Briant, E., N. Watson, and G. Philo. 2013. "Reporting Disability in the Age of Austerity: The Changing Face of Media Representation of Disability and Disabled People in the United Kingdom and the Creation of New 'Folk Devils." Disability \& Society 28 (6): 874-89.

B€ulow, P. 2008. "“You have to ask a little": Troublesome storytelling about contested illness." In Health, Illness and Culture: Broken Narratives, edited by L. C. Hyden, and J.

Brockmeier. New York: Routledge.

Cameron, D. The Rt. Hon. 2010. PM speech on wellbeing. Prime Minister's Office, 10

Downing Street. Delivered on November 25, 2010.

Charmaz, K. 1983. "Loss of Self: A Fundamental Form of Suffering in the Chronically III."

Sociology of Health \& Illness 5 (2): 168-95. no.

Charmaz, K. 2014. Constructing Grounded Theory. 2nd ed. London: Sage.

Clifton, A., J. Reynolds, J. Remnant, and J. Noble. 2013. "The Age of Austerity: The Impact of Welfare Reform on People in the North East of England." Mental Health Nursing 33 (6):

$30-2$.

Corcoran, P., E. Griffin, E. Arensman, A. Fitzgerald, and I. Perry. 2015. "Impact of the Economic Recession and Subsequent Austerity on Suicide and Self-Harm in Ireland: An Interrupted Time Series Analysis." International Journal of Epidemiology 44 (3): 969-77. de Wolfe, P. 2012. "Reaping the Benefits of Sickness? Long-Term Illness and the Experience of Welfare Claims." Disability \& Society 27 (5): 617-30.

Duffy, S. 2013. A Fair Society? How the Cuts Target Disabled People. Sheffield: The Centre for Welfare Reform. Duffy, S. 2014. Counting the Cuts: What the Government Doesn't Want the Public to Know. Sheffield: The Centre for Welfare Reform.

DWP (Department for Work and Pensions). 2012. The Welfare Reform Act. UK

Government/National Archives.

DWP (Department for Work and Pensions). 2016. Welfare Reform and Work Act 2016. UK Government/National Archives.

Dwyer, P. 2010. Understanding Social Citizenship: Themes and Perspectives in Policy and Practice. 2nd Edition. Bristol: Policy Press.

Dwyer, P., K. Jones, J. McNeill, L. Scullion, and A. Stewart. 2016. First Wave Findings:

Disability and Conditionality. Economic and Social Research Council. www.welfareconditionality.ac.uk.

Fitch, C., S. Hamilton, P. Bassett, and R. Davey. 2011. "The Relationship between Personal

Debt and Mental Health: A Systematic Review." Mental Health Review Journal 16 (4):

153-66.

Garthwaite, K. 2011. "The Language of Shirkers and Scroungers?' Talking about Illness,

Disability and Coalition Welfare Reform." Disability \& Society 26 (3): 369-72.

Garthwaite, K. 2014. "Fear of the Brown Envelope: Exploring Welfare Reform with Long- 
Term Sickness Benefits Recipients." Social Policy \& Administration 48 (7): 782-98.

Garthwaite, K. 2015. "Becoming Incapacitated? Long-Term Sickness Benefit Recipients and the Construction of Stigma and Identity Narratives." Sociology of Health \& IIIness 37 (1): 1-13.

Garthwaite, K. 2015b. "Keeping Meself to Meself'- How Social Networks Can Influence Narratives of Stigma and Identity for Long-Term Sickness Benefits Recipients." Social Policy \& Administration 49 (2): 199-212.

Garthwaite, K., C. Bambra, and J. Warren. 2013. "The Unwilling and the Unwell'? Exploring Stakeholders' Perceptions of Working with Long Term Sickness Benefits Recipients." Disability \& Society 28 (8): 1104-17.

Gentleman, A. 2012. "Atos Assessors Told to Keep Disability Benefit Approvals Low, Film Suggests." The Guardian, July 27, 2012. www.theguardian.com/society/2012/jul/27/disability-benefitassessors-film.

Goffman, E. 1963. Stigma: Notes on the Management of Spoiled Identity. Harmondsworth: Penguin.

Grover, C., and L. Piggott. 2010. "From Incapacity Benefit to Employment and Support Allowance: social Sorting, Sickness and Impairment and Social Security." Policy Studies 31 (2): 265-82.

Grover, C., and L. Piggott. 2013. "Employment and Support Allowance: capability, Personalisation and Disabled People in the UK." Scandinavian Journal of Disability Research 15 (2): 170-84.

HM Treasury 2012. Budget 2012. London: The Stationery Office.

Hudson, J. R., R. Patrick, and E. Wincup. 2016. "Introduction to Themed Special Issue:

Exploring 'Welfare' Attitudes and Experiences." Journal of Poverty and Social Justice 24 (3): 215-26.

KHP (King's Health Partners). 2016. The Overlap Between Mental and Physical Health. www.kingshealthpartners.org/our-work/mind-and-body/resources.

Litchfield, P. 2013. An Independent Review of the Work Capability Assessment - Year Four. London: Department for Work and Pensions.

Loopstra, R., A. Reeves, D. Taylor-Robinson, B. Barr, M. McKee, and D. Stuckler. 2015. Austerity, Sanctions, and the Rise of Food Banks in the UK. BMJ (Clinical research ed.), 350.

Marks, A., S. Cowan, and G. Maclean. 2017. Understanding the Impact of Welfare Reforms in Scotland for Individuals with Mental Health Conditions. Centre for Research on Work and Wellbeing (CRoWW), Heriot-Watt University and Employment Research Institute (ERI), Edinburgh Napier University.

McCartney, M. 2012. "The Disturbing Truth about Disability Assessments." BMJ 345: e5347. McCartney, M. 2015. "Who's Measuring the Harm Caused by the New Benefits System?" BMJ 350: h280.

McEnhill, L., and V. Byrne. 2014. "Beat the Cheat': Portrayals of Disability Benefit Claimants in Print Media." Journal of Poverty and Social Justice 22 (2): 99-110.

Moffatt, S., and E. Noble. 2015. "Work or Welfare after Cancer? Explorations of Identity and Stigma." Sociology of Health \& Illness 37 (8): 1191-205.

Morris, R. 2013. "Unjust, Inhumane and Highly Inaccurate': The Impact of Changes to Disability Benefits and Services-Social Media as a Tool in Research and Activism."

Disability \& Society 28 (5): 724-8.

NPI (New Policy Institute) 2016. Monitoring poverty and social exclusion 2016: Annual Report. The Joseph Rowntree Foundation.

Park, A., E. Clery, J. Curtice, M. Phillips, and D. Utting, eds. 2012. British Social Attitudes: the 29th Report. London: National Centre for Social Research.

Patrick, R. 2014. "Working on Welfare: Findings from a Qualitative Longitudinal Study into the Lived Experiences of Welfare Reform in the UK." Journal of Social Policy 43 (4): 705-25.

Patrick, R. 2016. "Living with and Responding to the 'Scrounger' Narrative in the UK: Exploring Everyday Strategies of Acceptance, Resistance and Deflection." Journal of Poverty and Social Justice 24 (3): 245-59.

Patrick, R. 2017. "Wither Social Citizenship? Lived Experiences of Citizenship in/Exclusion 
for Recipients of out-of-Work Benefits." Social Policy and Society 16(2): 293-304.

Pemberton, S., E. Fahmy, E. Sutton, and K. Bell. 2016a. Endless Pressure: Life on a Low Income in Austere Times. Social Policy \& Administration 51(7): 1156-1173.

Pemberton, S., E. Fahmy, E. Sutton, and K. Bell. 2016. "Navigating the Stigmatised Identities of Poverty in Austere Times: Resisting and Responding to Narratives of Personal Failure." Critical Social Policy 36 (1): 21-37.

Power, A. 2016. "Disability, (Auto) Mobility and Austerity: Shrinking Horizons and Spaces of Refuge." Disability \& Society 31 (2): 1-284.

PAA (Psychologists Against Austerity) 2015. The Psychological Impact of Austerity: A

Briefing Paper. Psychologists Against Austerity.

Reed, H., and J. Portes. 2014. Cumulative Impact Assessment. London: Equality and Human Rights Commission.

Richardson, T., P. Elliott, and R. Roberts. 2013. "The Relationship between Personal Unsecured Debt and Mental and Physical Health: A Systematic Review and MetaAnalysis." Clinical Psychology Review 33 (8): 1148-62.

Roulstone, A. 2015. "Personal Independence Payments, Welfare Reform and the Shrinking Disability Category." Disability \& Society 30 (5): 673-88.

Royston, S. 2017. Broken benefits: what's gone wrong with welfare reform. Bristol: Policy Press.

Shefer, G., C. Henderson, M. Frost-Gaskin, and R. Pacitti. 2016. “Only Making Things Worse: A Qualitative Study of the Impact of Wrongly Removing Disability Benefits from People with Mental IIIness." Community Mental Health Journal 52(7), 834-841.

Shildrick, T., and R. MacDonald. 2013. "Poverty Talk: how People Experiencing Poverty Deny Their Poverty and Why They Blame 'the Poor." The Sociological Review 61 (2): 285-303.

Spicker, P. 2011. How Social Security Works: An Introduction to Benefits in Britain. Bristol: Policy Press.

Stack, S., and I. Wasserman. 2007. "Economic Strain and Suicide Risk: A Qualitative Analysis." Suicide and Life-Threatening Behavior 37 (1): 103-12.

Stone, D. A. 1984. The Disabled State. Philadelphia: Temple University Press.

Taylor-Gooby, P., and G. Stoker. 2011. "The Coalition Programme: A New Vision for Britain or Politics as Usual?" The Political Quarterly 82 (1): 4. January-March 2011.

Thomas, P. 2011. "Mate Crime': Ridicule, Hostility and Targeted Attacks against Disabled People." Disability \& Society 26 (1): 107-11.

Wade, A. 1997. "Small Acts of Living: Everyday Resistance to Violence and Other Forms of Oppression." Contemporary Family Therapy 19 (1): 23-39.

Wright, S. 2016. "Conceptualising the Active Welfare Subject: welfare Reform in Discourse, Policy and Lived Experience." Policy \& Politics 44 (2): 235-52.

UNCESCR (UN Committee on Economic, Social and Cultural Rights). 2016. Concluding observations on the sixth periodic report of the United Kingdom of Great Britain and Northern Ireland.

UNCRPD (UN Committee on the Rights of Persons with Disabilities). 2016. Inquiry concerning the United Kingdom of Great Britain and Northern Ireland carried out by the Committee under article 6 of the Optional Protocol to the Convention. Report of the Committee.

UNCRC (United Nations Committee on the Rights of the Child). 2016. Concluding observations on the fifth periodic report of the United Kingdom of Great Britain and Northern Ireland. 
Figure 1. Grounded theory model.

\section{NAVIGATING A DEHUMANISING SYSTEM}

\section{LIVING IN A JUDGEMENTAL SOCIETY}

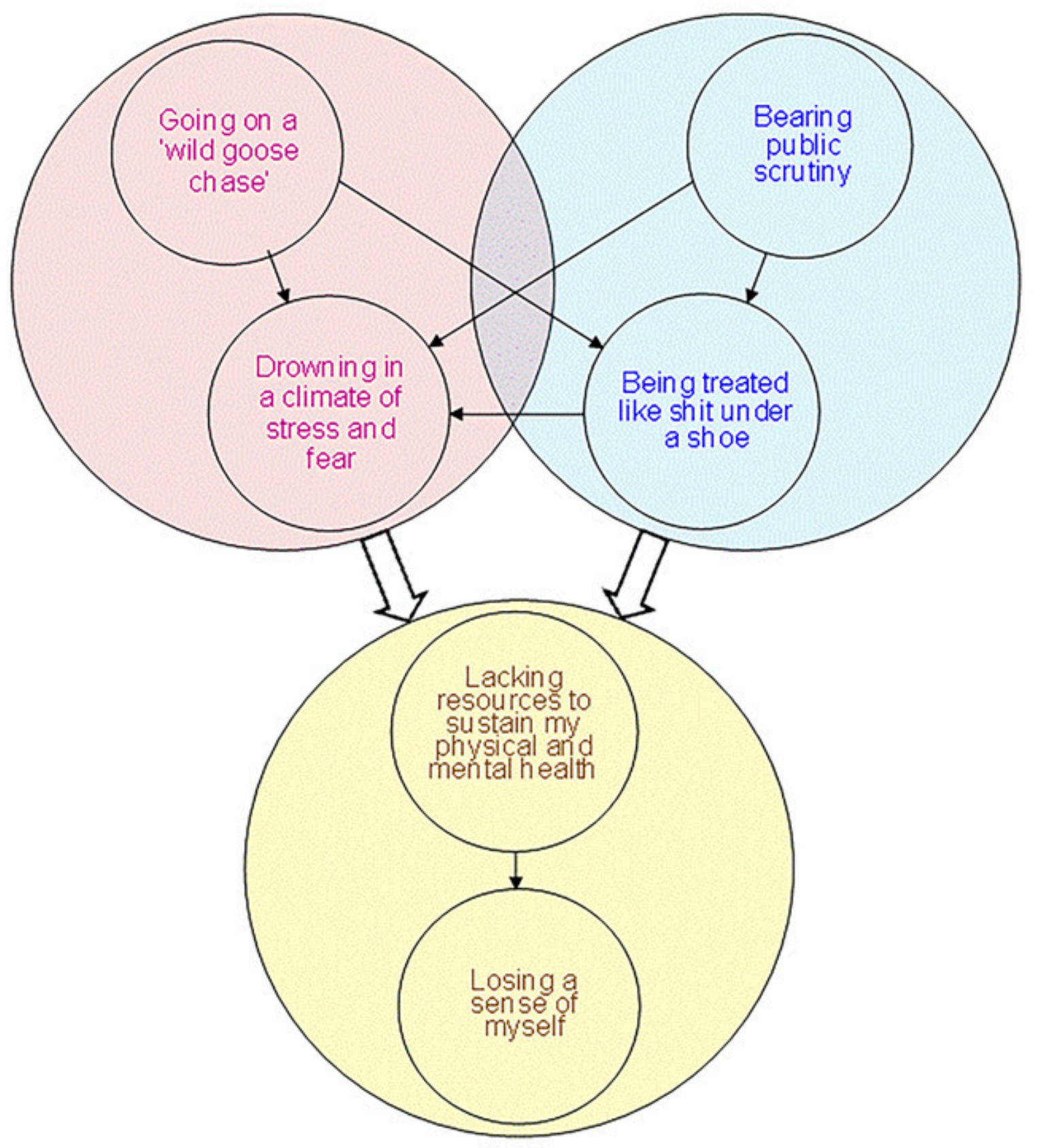

\section{CLINGING ONTO MY SENSE OF SELF}


Table 1. Participants' demographic information.

\begin{tabular}{|c|c|c|c|c|c|c|c|}
\hline Name $^{*}$ & Gender & Age & Ethnicity & $\begin{array}{l}\text { Marital } \\
\text { status }\end{array}$ & $\begin{array}{l}\text { Living with } \\
\text { /Dependents }\end{array}$ & $\begin{array}{l}\text { (Previous) } \\
\text { Career }\end{array}$ & $\begin{array}{l}\text { Benefit } \\
\text { issues }\end{array}$ \\
\hline Adrienne & Female & 57 & $\begin{array}{l}\text { White } \\
\text { /British }\end{array}$ & Divorced & $\begin{array}{l}\text { Adult daughter } \\
\& \\
\text { granddaughter } \\
\text { aged 1 }\end{array}$ & Prev. Teacher & ESA \\
\hline Bryony & Female & 47 & White & Single & $N / A$ & Performer & $\begin{array}{l}\text { ILF, } \\
\text { Access to } \\
\text { Work }\end{array}$ \\
\hline Caroline & Female & 52 & $\begin{array}{l}\text { White } \\
\text { /British }\end{array}$ & Single & N/A & Administrator & ESA \\
\hline Dean & Male & 61 & $\begin{array}{l}\text { White } \\
\text { British }\end{array}$ & Married & Wife & Prev. Builder & PIP \\
\hline Eve & Female & 59 & $\begin{array}{l}\text { White } \\
\text { /British }\end{array}$ & Divorced & $\mathrm{N} / \mathrm{A}$ & $\begin{array}{l}\text { Prev. Clerical } \\
\text { worker }\end{array}$ & ESA \\
\hline Frankie & Female & 38 & $\begin{array}{l}\text { Black Afro- } \\
\text { Caribbean }\end{array}$ & Single & N/A & Prev. Solicitor & PIP, ESA \\
\hline Grace & Female & 48 & $\begin{array}{l}\text { White } \\
\text { /British }\end{array}$ & Single & N/A & Law degree & PIP, ESA \\
\hline Hazel & Female & 68 & $\begin{array}{l}\text { White } \\
\text { /British }\end{array}$ & Widowed & $\mathrm{N} / \mathrm{A}$ & $\begin{array}{l}\text { Retired social } \\
\text { worker }\end{array}$ & PIP \\
\hline Irene & Female & 56 & $\begin{array}{l}\text { White } \\
\text { /British }\end{array}$ & Single & Adult daughter & $\begin{array}{l}\text { Prev. Insurance } \\
\text { worker }\end{array}$ & PIP \\
\hline Jonathan & Male & 60 & $\begin{array}{l}\text { White } \\
\text { British }\end{array}$ & $\begin{array}{l}\text { Long-term } \\
\text { partner }\end{array}$ & $\begin{array}{l}\text { Partner \& } \\
\text { daughter aged } \\
7\end{array}$ & Prev. Engineer & PIP, ESA \\
\hline Kelvin & Male & 28 & Arab & $\begin{array}{l}\text { In } \\
\text { relationship }\end{array}$ & $\begin{array}{l}\text { Partner. } \\
\text { Daughter aged } \\
5 \text { living with } \\
\text { mother }\end{array}$ & Journalist & PIP \\
\hline \begin{tabular}{|l} 
Louise \\
\end{tabular} & Female & 44 & $\begin{array}{l}\text { White } \\
\text { /British }\end{array}$ & Single & $N / A$ & $\begin{array}{l}\text { Volunteer \& } \\
\text { artist }\end{array}$ & PIP, ESA \\
\hline Molly & Female & 31 & $\begin{array}{l}\text { White } \\
\text { /British }\end{array}$ & Partner & N/A & $\begin{array}{l}\text { Trainee } \\
\text { Therapist }\end{array}$ & PIP \\
\hline Nicola & Female & 31 & $\begin{array}{l}\text { White } \\
\text { /British }\end{array}$ & Single & $N / A$ & $\begin{array}{l}\text { Postgraduate } \\
\text { student }\end{array}$ & $\begin{array}{l}\text { Waitfor } \\
\text { PIP }\end{array}$ \\
\hline Oliver & Male & 31 & $\begin{array}{l}\text { White } \\
\text { /British }\end{array}$ & Single & N/A & Journalist & PIP \\
\hline
\end{tabular}

*Pseudonyms are being used to maintain participants' confidentiality 
This is the accepted version of: Saffer, J. Nolte, L., \& Duffy, S. (2018). Living on a knife edge: The responses of people with physical health conditions to changes in disability benefits. Disability and Society. https://doi.org/10.1080/09687599.2018.1514292

\section{Table 2. Findings.}

Domain

Navigating a dehumanising system

Living in a judgemental society

Clinging onto my sense of self
Sub-domain

Going on a 'wild goose chase'

Drowning in a climate of stress and fear

Bearing public scrutiny

Being treated like shit under a shoe

Lacking resources to sustain my physical and mental health

Losing a sense of myself 